ISSN 0258-7122 (Print), 2408-8293 (Online)

Bangladesh J. Agril. Res. 43(2): 309-322, June 2018

\title{
ADOPTION AND PROFITABILITY OF BARI RELEASED POTATO VARIETIES IN NORTHERN REGION OF BANGLADESH
}

\author{
Q. M. S. ISLAM ${ }^{1}$, M. A. MATIN ${ }^{2}$, M. S. H. SIDDIQUEE ${ }^{3}$ \\ AND M. T. ISLAM ${ }^{4}$
}

\begin{abstract}
The study was conducted in three potato growing areas in nothern districts of Bangladesh namely Rajshahi, Rangpur and Thakurgaon. Data were collected during 2016-17 to assess the level of adoption, profitability, farmers attitude towards the cultivation of BARI released potato varieties and to explore the constraints to potato cultivation. The study revealed that $59 \%$ potato areas were covered by BARI Alu-7 variety. The varieties BARI Alu-13, BARI Alu-25 and BARI Alu- 8 covered $14 \%, 14 \%$ and $12 \%$ of the potato areas respectively. The adoption level of seed rate, gypsum and boron were found high which adoption score were 95, 72 and 71. The level adoption of urea, TSP and MoP were over used which adoption score were 103,138 and 110. The adoption levels of cowdung and zinc sulphate were found medium which adoption score were 50 and 61. Only $37 \%$ farmers used potato seeds from their own source. Per hectare total cost of BARI released potato cultivation was Tk. 204003 and variable cost was Tk. 161033. The major share of cost was seed (31\%) followed by fertilizer (13\%) and land use $(11 \%)$. Per hectare average yield of potato was 28 ton with gross return Tk. 249819 and gross margin Tk. 88786. The net return of potato cultivation was Tk. 45816 per hectare. The benefit cost ratio was 1.22. Infestation of insect and diseases, non-availability of quality seed, high price of seed and inadequate storage facilities were the major constraints to potato cultivation.
\end{abstract}

Keywords: Potato, Adoption, Profitability, Constraints.

\section{Introduction}

Potato (Solanum tuberosum) is a leading vegetable crop in the world and occupies top-most position after rice and wheat both in respect of production and consumption (Aktar et al., 1998). It is the third largest food crop in Bangladesh and has recently occupied an important place in the list of major food and cash crops of Bangladesh (Ali and Haque, 2011). The crop ranks first among the vegetables in Bangladesh and its area and production are increasing day by day (BBS, 2016). The total potato area is 475709 ha and production is $9474000 \mathrm{M}$. tons in Bangladesh. The growth rate of area, production and yield were $6.4 \%$, 9.5\% and 3.1\% respectively during the period from 1995 to 2016 (Table 1). Ensuring food security for all is one of the major challenges in Bangladesh today.

${ }^{1}$ Principal Scientific Officer and ${ }^{2}$ Chief Scientific Officer, Agricultural Economics Division, Bangladesh Agricultural Research Institute (BARI), Gazipur, ${ }^{3}$ Senior Assistant Director, National Agriculture Training Academy (NATA), Gazipur and ${ }^{3}$ Scientific Officer, Promology Division, HRC, BARI, Gazipur, Bangladesh. 
So, to ensure adequate food supply, it is necessary to give thrust to increase food production using BARI released crop varieties and recommended production practices. Potato is a short duration and labour intensive crop. In fact, short cycle of potato frees the land for cultivating other crops. The Tuber Crop Research Centre of BARI released different HYV potato varieties which have good yield potential and tolerant to insect pests and diseases.

Table 1. Area, production and yield of potato in Bangladesh

\begin{tabular}{lcccc}
\hline Year & Acreage (ha) & Production (M. tons) & Yield (t/ha) \\
\hline $1995-96$ & 132389 & 1492000 & 11.27 \\
$1996-97$ & 134008 & 1508000 & 11.25 \\
$1997-98$ & 136437 & 1553000 & 11.38 \\
$1998-99$ & 244939 & 2762000 & 11.28 \\
$1999-00$ & 243320 & 2933000 & 12.05 \\
$2000-01$ & 248988 & 3216000 & 12.92 \\
$2001-02$ & 237652 & 2994000 & 12.60 \\
$2002-03$ & 245344 & 3386000 & 13.80 \\
$2003-04$ & 270850 & 3908000 & 14.43 \\
$2004-05$ & 326316 & 4856000 & 14.88 \\
$2005-06$ & 301215 & 4161000 & 13.81 \\
$2006-07$ & 345344 & 5167000 & 14.96 \\
$2007-08$ & 402024 & 6648000 & 16.54 \\
$2008-09$ & 395547 & 5268000 & 13.32 \\
$2009-10$ & 434818 & 7930000 & 18.24 \\
$2010-11$ & 460324 & 8326000 & 18.09 \\
$2011-12$ & 430364 & 8205000 & 19.07 \\
$2012-13$ & 444534 & 8603000 & 19.35 \\
$2013-14$ & 462348 & 8950000 & 19.36 \\
$2014-15$ & 471255 & 9254000 & 19.64 \\
$2015-16$ & 475709 & 9474000 & 19.92 \\
\hline Mean & 318401 & 50408000 & 14.89 \\
Standard deviation & 115151 & 2658452 & 3.01 \\
Growth rate (\%) & 6.4 & 9.5 & 3.1 \\
\hline
\end{tabular}

Most of the varieties are not cultivated by the farmers because of various unknown reasons that need to be identified. The adoption of recommended practices of potato production by the farmers could easily raise food production and net income of the users (Amin and Islam, 2009). Usually farmers follow different levels of production technologies depending upon their infrastructural facilities and socioeconomic conditions which ultimately resulted in variability in yields of potato (Elias et al., 1992). Farmer's production performance depends on physical resources and technology available to them as well as existing farm 
management conditions. Efficient use of inputs and technologies could help farmers to get higher production from a given amount of resources. A very few studies were conducted (Begum et. al., 2017 and Haque et al., 2011) regarding the adoption of potato varieties in Bangladesh.

In view of the above discussion, the study attempted to achieve the following specific objectives: (i) to know the level of adoption of BARI released potato varieties at farm level; (ii) to know the agronomic practices of potatoes cultivation; (iii) to estimate the profitability of BARI released potato varieties; (iv) to evaluate the farmers attitude towards the cultivation of BARI released potato varieties and (v) to identify the socio- economic constraints of BARI released potato varieties adoption at farm level.

\section{Methodology}

\section{Study area selection:}

Sampling technique: Three districts, namely Rajshahi, Rangpur and Thakurgaon were purposively selected considering the major potato growing areas in northern region of Bangladesh. Again from each district three upazilas were selected considering the concentration of potato growers and easy access. From each upazila one block was also selected in consultation with the Upazila Agriculture Officer. A list of potato growers from the selected block were collected with the help of DAE personnel. Thus a total of 135 samples were randomly selected for the interview.

Method of data collection: Data were collected by the experienced field investigators with direct supervision of the researchers using a pre-tested interview schedule for the period of 2016-2017. Both fixed cost and variable cost were taken into account in calculating cost of potato cultivation. Land use cost was calculated on the basis of per year existing lease value of land. The profitability of potato production was examined on the basis of gross margin, net return and benefit cost analysis.

Analytical technique: Farm level collected data were edited, summarized, tabulated and analyzed to fulfill the objectives of the study. In most cases, tabular method of analysis supported with appropriate statistical parameters such as average, ratio, percentages were used to present the results of the study. The adoptions of improved technologies were measured through three ways: variety adoption, acreage covered, and use of crop management technology (i.e. agronomic practices, time of operation, input use). For assessing the adoption of crop management technology, respondent farmers was grouped into three categories such as high adopter, medium adopter, and low adopter based on the mean index of the farmer with respect to each technology. A higher index was indicating a higher level of adoption, while a lower index was indicate a lower level of adoption of a technology. Adoption level were categorized for mean index $>100$ as over use; 70-100 as high, 50-69 as medium, and $<50$ as low. 


\section{Calculation of adoption index}

Adoption index was calculated using the following formula (Gupta and Chowdhi, 2002:

Adoption Index $=\frac{100}{\text { Recommended dose }} \times$ Farmers dose

\section{Profitability analysis}

Profitability of potato was analyzed to compare the return received by the farmers.

\section{a. Measurement of cost and return from potato cultivation}

Equations for cost analysis are as follows

$$
\begin{aligned}
& \text { Variable Cost }=V C_{i}=\sum\left(X_{i} P_{i}\right) \\
& T V C_{i}=V C_{i}+I O C_{\tilde{i}} \\
& T C_{\bar{i}}=T V C_{\tilde{i}}+T F C_{\tilde{i}}
\end{aligned}
$$

Where, $\mathrm{TC}_{\mathrm{i}}=$ Total cost $(\mathrm{Tk} / \mathrm{ha})$

$$
\begin{aligned}
& \mathrm{TVC}_{\mathrm{i}}=\text { Total variable cost }(\mathrm{Tk} / \mathrm{ha}) \\
& \mathrm{TFC}_{\mathrm{i}}=\text { Total fixed cost }(\mathrm{Tk} / \mathrm{ha}) \\
& \mathrm{VC}_{\mathrm{i}}=\text { Variable cost }(\mathrm{Tk} / \mathrm{ha}) \\
& \mathrm{IOC}_{\mathrm{i}}=\text { Interest of operating capital }(\mathrm{Tk} / \mathrm{ha}) \\
& \mathrm{X}_{\mathrm{i}}=\text { Quantity of inputs }(\mathrm{kg}) \\
& \mathrm{P}_{\mathrm{i}}=\text { Price of inputs }(\mathrm{Tk} / \mathrm{kg}) \\
& \mathrm{i}=\text { Number of farmers }(1.2 .3 \ldots \ldots . . \mathrm{n})
\end{aligned}
$$

Equations for profitability analysis

Gross retum $=G R_{\tilde{i}}=Y_{i} P_{\tilde{i}}$

Net returm $=G R_{\dot{i}}-T C_{\dot{i}}$

Gross margin $=G R_{i}-V C_{i}$

Where,

$$
\begin{aligned}
& \mathrm{GR}_{\mathrm{i}}=\text { Gross return }(\mathrm{Tk} / \mathrm{ha}) \\
& \mathrm{P}_{\mathrm{i}}=\text { Price }(\mathrm{Tk} / \mathrm{kg}) \text { received by } i \text { th farmer }
\end{aligned}
$$

$\mathrm{Y}_{\mathrm{i}}=$ Quantity $(\mathrm{kg} / \mathrm{ha})$ produced 


\section{Results and Discussion}

\section{Adoption of potato varieties}

Within the study areas, the sample farmers adopted BARI released potato varieties such as BARI Alu-7, BARI Alu-13, asterisk and BARI Alu-8. Within the sample farmers on an average, 59\% area was covered by BARI Alu-7. Highest area coverage $(92 \%)$ by BARI Alu-7 was found at Rajshahi followed by Rangpur and Thakurgaon. Area coverage of both BARI Alu-13 and BARI Alu-25 were 14\% (Table 2). The farmers of Rangpur mostly cultivated BARI Alu-7 and BARI Alu25 varieties as a result BARI Alu-8 variety adoption was low. The local variety potato were Lalsheet, Sheet Bilatee, Lalpakri etc. It was mentioned that farmers choice BARI Alu-7 variety due to high price, good test and high market demand. Farmer choose BARI Alu-13 for short duration, less disease infestation and low risk in cultivation. They cultivated BARI Alu-25 for high yield attractive colour and high demand in Rangpur. The farmers in the study areas also cultivated BARI Alu-8 variety for higher price and good test. It was observed that though BARI released more than 70 varieties, the farmers adopted only four varieties. Farmers of the study areas were not aware about the latest released varieties of potato.

Table 2. Adoption of area of BARI released potato varieties in northern region of Bangladesh

\begin{tabular}{l|c|c|c|c}
\hline \multirow{2}{*}{\multicolumn{1}{c}{ Variety }} & \multicolumn{4}{c}{ Adoption of area (\%) } \\
\cline { 2 - 5 } & Rajshahi & Rangpur & Thakurgaon & All \\
\hline BARI Alu-7 & 92 & 40 & 15 & 59 \\
BARI Alu-13 & - & 15 & 37 & 14 \\
BARI Alu-25 & 2 & 35 & 20 & 14 \\
BARI Alu-8 & 5 & 9 & 25 & 12 \\
Local* & 1 & 1 & 3 & 1 \\
\hline
\end{tabular}

* Lalsheet, Sheet Bilatee, Lalpakri etc.

On an average, $47 \%$ farmers adopted BARI Alu-7 variety followed by BARI Alu-13 (39\%) BARI Alu-25 (31\%) and BARI Alu-8 (30\%) (Table 3). Among the locations BARI Alu-7 was popular at Rajshahi(73\%), BARI Alu-25 at Rangpur and BARI Alu-13 at Thakurgaon.

Table 3. Farmers adopted different potato varieties in some selected areas of Bangladesh

\begin{tabular}{l|ccccc}
\hline \multirow{2}{*}{\multicolumn{1}{c}{ Variety }} & \multicolumn{4}{c}{ \% farmers responded } \\
\cline { 2 - 5 } & Rajshahi & Rangpur & Thakurgaon & All \\
\hline BARI Alu-7 & 73 & 44 & 22 & 47 \\
BARI Alu-13 & - & 40 & 78 & 39 \\
BARI Alu-25 & 18 & 51 & 24 & 31 \\
BARI Alu-8 & 31 & 13 & 44 & 30 \\
Local & 4 & 2 & 18 & 8 \\
\hline
\end{tabular}

* Lalsheet, Sheet Bilatee, Lalpakri etc. 


\section{Technology used in potato production}

The existing level of technology adoption in terms of agronomic practices, time of operation and input use are essential for achieving higher yield and return. The potato farmers in the study areas ploughed their lands with the help of power tiller and tractor.

Table 4. Adoption of crop management technologies in potato cultivation in the study areas

\begin{tabular}{|c|c|c|c|c|c|}
\hline \multirow{2}{*}{ Technology } & \multicolumn{4}{|c|}{$\%$ Farmers responded and adoption score } & \multirow{2}{*}{$\begin{array}{c}\text { Adoption } \\
\text { level }\end{array}$} \\
\hline & $\begin{array}{c}\text { Rajshahi } \\
(\mathrm{n}=45)\end{array}$ & $\begin{array}{c}\text { Rangpur } \\
(\mathrm{n}=45)\end{array}$ & $\begin{array}{l}\text { Thakurgaon } \\
(\mathrm{n}=45)\end{array}$ & $\begin{array}{c}\text { All } \\
(\mathrm{n}=135)\end{array}$ & \\
\hline \multicolumn{6}{|l|}{ Ploughing: } \\
\hline Recommended (4) & $16(7)$ & $55(25)$ & $18(8)$ & $30(40)$ & \\
\hline Below recommendation > (4) & $4(2)$ & $8(18)$ & $2(4)$ & 12(9) & \\
\hline Above recommendation $<(4)$ & $80(36)$ & $27(12)$ & $78(35)$ & $61(83)$ & \\
\hline Adoption index & 139 & 103 & 126 & 123 & Over use \\
\hline \multicolumn{6}{|l|}{ Sowing date : } \\
\hline Recommended (Nov.1-30) & $78(35)$ & $27(12)$ & $93(42)$ & $66(89)$ & \\
\hline $\begin{array}{cc}\text { Below } & \text { recommendation } \\
\text { (Before Nov. 1) } & \end{array}$ & - & - & - & - & \\
\hline $\begin{array}{l}\text { Above recommendation (After } \\
\text { Nov.30) }\end{array}$ & $22(10)$ & $73(33)$ & $7(3)$ & $34(46)$ & \\
\hline Adoption index & 89 & 101 & 71 & 87 & High \\
\hline
\end{tabular}

Note: Technology adoption was categorized for mean index $>100$ as overuse, $70-100$ as high; 50-69 as medium and $<50$ as low.

Figures in the parentheses indicate number of farmer responded.

The number of ploughing varied from farm to farm and location to location. Four times ploughing is recommended for potato cultivation. Based on the mean index, land preparation secured the over ploughing level of adoption for cultivation. On an average, only $30 \%$ farmers ploughed their land 4 times. More than 4 times ploughig was done by $61 \%$ farmers. Sowing was started from the $1^{\text {st }}$ week of November and continued up to the $3^{\text {rd }}$ week of December. About $93 \%$ farmer of Thakurgaon and 78\% farmers of Rajshahi district had plant their seed in optimum period (Table 4). Adoption level of ploughing and sowing date was found over use and high respectively. About $46 \%$ farmers followed recommended seed rate, whereas $43 \%$ farmer used above recommendation (Table 5). Only 8\% farmers used recommended doses (Kamal et al., 2012). of cowdung (1.5-2.0 t/ha) in their plots. About $48 \%$ of the farmers used more than recommended dose and $44 \%$ farmers used lower than recommended doses of cowdung. 
Table 5. Adoption of recommended seed rate and fertilizer in potato cultivation in the study areas

\begin{tabular}{|c|c|c|c|c|c|}
\hline \multirow[b]{2}{*}{ Technology } & \multicolumn{4}{|c|}{$\%$ Farmers responded and adoption score } & \multirow{2}{*}{$\begin{array}{c}\text { Adoption } \\
\text { level }\end{array}$} \\
\hline & $\begin{array}{l}\text { Rajshahi } \\
(n=45)\end{array}$ & $\begin{array}{c}\text { Rangpur } \\
(\mathrm{n}=45)\end{array}$ & $\begin{array}{c}\text { Thakurgaon } \\
(\mathrm{n}=45)\end{array}$ & $\begin{array}{c}\text { All } \\
(n=135)\end{array}$ & \\
\hline \multicolumn{6}{|l|}{ Seed rate: } \\
\hline Recommended (1.5-2.0 t/ha) & $60(27)$ & $40(18)$ & $38(17)$ & $46(62)$ & \\
\hline Below Recommended & $13(6)$ & $13(6)$ & $7(3)$ & $11(15)$ & \\
\hline Above Recommended & $27(12)$ & $47(21)$ & $55(25)$ & $43(58)$ & \\
\hline Adoption index & 91 & 92 & 102 & 95 & High \\
\hline \multicolumn{6}{|l|}{ Cowdung: } \\
\hline Recommended (8-10 t/ha) & - & $5(2)$ & $15(6)$ & $8(8)$ & \\
\hline Below recommendation $(<8 \mathrm{t} / \mathrm{ha}$ & $67(8)$ & $54(22)$ & $27(11)$ & $44(4)$ & \\
\hline Above recommendation $(>10 \mathrm{t} / \mathrm{ha})$ & $33(4)$ & $41(17)$ & $58(24)$ & $48(45)$ & \\
\hline Adoption index & 15 & 61 & 73 & 50 & Medium \\
\hline \multicolumn{6}{|l|}{ Urea: } \\
\hline Recommended (220-250 kg/ha) & $7(3)$ & $18(8)$ & $20(9)$ & $15(20)$ & \\
\hline Below recommendation $(<220 \mathrm{~kg} / \mathrm{ha}$ & $22(10)$ & $2(1)$ & $7(3)$ & $10(14)$ & \\
\hline Above recommendation (>250 kg/ha) & $71(32)$ & $80(36)$ & $73(33)$ & $75(101)$ & \\
\hline Adoption index & 96 & 120 & 93 & 103 & Over use \\
\hline \multicolumn{6}{|l|}{ TSP: } \\
\hline Recommended ( 120-150 kg/ha) & $23(8)$ & $19(4)$ & $4(2)$ & $14(14)$ & \\
\hline Below recommendation (<120 kg/ha) & $23(8)$ & - & $2(1)$ & $9(9)$ & \\
\hline Above recommendation $(>150 \mathrm{~kg} / \mathrm{ha})$ & $54(19)$ & $81(17)$ & $94(42)$ & $77(78)$ & \\
\hline Adoption index & 112 & 93 & 208 & 138 & Over use \\
\hline \multicolumn{6}{|l|}{ MoP: } \\
\hline Recommended (220-250 kg/ha) & $4(2)$ & $18(8)$ & $27(12)$ & $16(22)$ & \\
\hline Below recommendation (<220 kg/ha) & $18(8)$ & - & $24(11)$ & $14(19)$ & \\
\hline Above recommendation $(>250 \mathrm{~kg} / \mathrm{ha})$ & $78(35)$ & $82(36)$ & $49(22)$ & $70(93)$ & \\
\hline Adoption index & 119 & 124 & 86 & 110 & Over use \\
\hline \multicolumn{6}{|l|}{ Gypsum: } \\
\hline Recommended (100-120 kg/ha) & $5(2)$ & $12(5)$ & $4(1)$ & $8(8)$ & \\
\hline Below Recommended ( $<100 \mathrm{~kg} / \mathrm{ha}$ & $49(19)$ & $29(12)$ & $43(12)$ & $40(43)$ & \\
\hline Above Recommended (>120 kg/ha) & $46(18)$ & $59(24)$ & $53(15)$ & $62(57)$ & \\
\hline Adoption index & 69 & 87 & 61 & 72 & High \\
\hline \multicolumn{6}{|l|}{ Zinc: } \\
\hline Recommended (8-10 kg/ha) & $8(3)$ & $56(23)$ & $27(8)$ & $32(34)$ & \\
\hline Below recommendation $(<8 \mathrm{~kg} / \mathrm{ha}$ & $49(18)$ & $12(5)$ & $33(10)$ & $30(33)$ & \\
\hline Above recommendation (>10 t/ha) & $43(16)$ & $32(13)$ & $40(12)$ & $38(41)$ & \\
\hline Adoption index & 57 & 71 & 53 & 61 & Medium \\
\hline \multicolumn{6}{|l|}{ Boron: } \\
\hline Recommended (8-10 kg/ha) & $3(1)$ & $40(17)$ & $32(11)$ & $25(29)$ & \\
\hline Below recommendation $(<8 \mathrm{~kg} / \mathrm{ha}$ & $38(15)$ & $20(8)$ & $32(11)$ & $30(34)$ & \\
\hline Above recommendation (>10 kg/ha) & $59(23)$ & $40(17)$ & $35(12)$ & $45(52)$ & \\
\hline Adoption index & 67 & 83 & 63 & 71 & High \\
\hline
\end{tabular}

Note: Technology adoption was categorized for mean index>100 as overuse, 70-100 as high; 50-69 as medium and $<50$ as low. Figures in the parentheses indicate number of farmer responded. 
Table 6. Agronomic practices of potato cultivation in the study areas

\begin{tabular}{|c|c|c|c|c|}
\hline \multirow{2}{*}{ Practices } & \multicolumn{3}{|c|}{ Farmer responded $(\%)$} & \multirow{2}{*}{$\begin{array}{l}\text { All } \\
\text { All }\end{array}$} \\
\hline & Rajshahi & Rangpur & Thakurgaon & \\
\hline \multicolumn{5}{|l|}{ Ploughing method: } \\
\hline Power tiller & 60 & 42 & 7 & 36 \\
\hline Tractor & 40 & 58 & 93 & 64 \\
\hline \multicolumn{5}{|l|}{ Seed source } \\
\hline Own & 34 & 40 & 38 & 37 \\
\hline Market & 2 & 27 & 18 & 15 \\
\hline Neibours & 42 & 15 & 3 & 20 \\
\hline BADC & 2 & 7 & 13 & 8 \\
\hline Others* & 20 & 11 & 28 & 20 \\
\hline \multicolumn{5}{|l|}{ Earthing up (No.) : } \\
\hline One & 49 & 73 & 22 & 48 \\
\hline Two & 51 & 20 & 75 & 49 \\
\hline Three & - & 7 & 3 & 3 \\
\hline \multicolumn{5}{|c|}{ Pesticides application (No.): } \\
\hline $2-4$ & 7 & 7 & 33 & 16 \\
\hline $5-8$ & 78 & 45 & 65 & 62 \\
\hline $9-12$ & 15 & 48 & 2 & 22 \\
\hline \multicolumn{5}{|l|}{ Irrigation (No.): } \\
\hline $1-4$ & 22 & 95 & 93 & 70 \\
\hline $5-7$ & 78 & 5 & 7 & 30 \\
\hline
\end{tabular}

- Others means BRAC, Supreme seed, Ispahani, Research agro etc.

About $75 \%$ of the farmers used urea more than recommended dose. Fifteen percent farmers used recommended doses of urea $(220-250 \mathrm{~kg} / \mathrm{ha})$ in their plots and only $10 \%$ farmers used lower than recommended dose. Adoption level of urea was found slightly over use in the study areas with an adoption score 103. Most of the farmers (77\%) used TSP above the recommended rate (120-150 $\mathrm{kg} / \mathrm{ha}$ ). Only $14 \%$ farmers used recommended doses of TSP while $9 \%$ farmers used below recommended dose. Overall adoption score of TSP application was found $138 \%$, which indicates over use of TSP in the study areas. About $70 \%$ of the farmers used MoP above recommended dose. About $16 \%$ farmers used recommended doses of MoP (220-250 kg/ha) in their plots and only $14 \%$ farmers used lower than recommendation. As a result adoption level of MoP application found to be slightly over use in the study areas with an adoption score 110. About $8 \%$ farmers used recommended doses of gypsum (100-120 kg/ha) in their plots and $40 \%$ farmers used lower than recommended dose. Most of the farmers (62\%) used gypsum above than recommendation. Adoption level was found high in gypsum. About $32 \%$ and $25 \%$ farmers used recommended doses $(8-10 \mathrm{~kg} / \mathrm{ha})$ of Zinc and Boron in their plots. Adoption level was found 61 and $71 \%$ which indicates medium and high level of adoption respectively. 


\section{Agronomic practices}

Farmers in the study areas prepared their potato plots using power tiller and tractor. Sixty four percent farmers used tractor for land preparation which was higher in Thakurgaon (93\%) followed by Rangpur (58\%) and Rajshahi (40\%). Rest of the farmers (34\%) used power tiller (Table 6). About $37 \%$ farmers used their home supplied seed and rest of the farmers used seeds from different sources like local market, neibouring farmers, BADC, BRAC and seed companies. Generally one earthing up (48\%) which was more (73\%) in Rangpur or two earthing up (49\%) which was more $(75 \%)$ in Thakurgaon, was practiced by the farmers in the study areas. Sixty two percent farmers applied insecticides 5-8 times, 22\% applied 9-12 times and 16\% applied 3-4 times. Most of the famers (70\%) irrigated their field 1-4 times.

\section{Input use pattern}

The human labour used for producing potato was found to be 176 man days per hectare of which $41 \%$ were family supplied (Table 7). The use of human labor was highest in Rangpur (183 man-days/ha) followed by Rajshahi (179 mandays/ha) and Thakurgaon (166 man-days/ha). The average quantity of seed used by the farmers were $1904 \mathrm{~kg} / \mathrm{ha}$ which was similar to recommended doses (1.5$2.0 \mathrm{t} / \mathrm{ha}$ ) (Kabir et al., 2012). On average, farmers used $8075 \mathrm{~kg} / \mathrm{ha}$ of cowdung which was similar to recommended doses (8-10 t/ha). The farmers of Thakurgaon used cowdung slightly higher than recommended doses and Rajshahi farmers used very less amount of cowdung. It may be due to availability of cowdung to the farmers in those areas. They used chemical fertilizers like urea $(371 \mathrm{~kg} / \mathrm{ha})$, TSP (219 kg/ha), MoP (400 kg/ha), DAP (177 kg/ha) and gypsum (114 kg/ha). They used higher doses of urea, TSP and MoP and lower dose of gypsum than the recommended dose.

Table 7. Level of input used in HYV and local variety of potato cultivation in the study areas

\begin{tabular}{lccccc}
\hline \multicolumn{1}{c}{ Inputs } & Rajshahi & Rangpur & Thakurgaon & All \\
\hline \multicolumn{1}{c}{ Human labour: } & \multicolumn{3}{c}{} & \\
$\quad$ Own & 67 & 77 & 74 & 73 \\
$\quad$ Total & 112 & 106 & 92 & 103 \\
Seed (kg/ha) & 179 & 183 & 166 & 176 \\
Cow dung (kg/ha) & 1825 & 1851 & 2036 & 1904 \\
Urea (kg/ha) & 2194 & 9994 & 12039 & 8075 \\
TSP(kg/ha) & 331 & 443 & 339 & 371 \\
MoP (kg/ha) & 177 & 150 & 331 & 219 \\
DAP & 413 & 453 & 333 & 400 \\
Gypsum & 340 & 174 & 16 & 177 \\
Others & 98 & 148 & 98 & 114 \\
\hline
\end{tabular}

Source: Field Survey (2016-17) 
Table 8. Per hectare cost of cultivation of potato in the study areas

\begin{tabular}{lcc|c|c}
\hline \multirow{2}{*}{ Input costs } & \multicolumn{4}{|c}{ Taka per hectare } \\
\cline { 2 - 5 } & Rajshahi & Rangpur & Thakurgaon & All \\
\hline A. Variable cost: & \multicolumn{4}{c}{} \\
Land preparation & 15032 & 11678 & 14070 & $13927(7)$ \\
Hired human & 29277 & 26876 & 25819 & $27327(13)$ \\
labour & & & & \\
Seed & 67760 & 54658 & 68625 & $63681(31)$ \\
Manures & 1109 & 7367 & 8248 & $5575(3)$ \\
Fertilizers: & & & & \\
Urea & 5303 & 5744 & 5375 & $5825(3)$ \\
TSP & 3883 & 3589 & 8187 & $5220(2)$ \\
MoP & 6206 & 6765 & 4815 & $5929(3)$ \\
DAP & 8616 & 4654 & 389 & $4553(2)$ \\
Gypsum & 1393 & 1404 & 1113 & $1303(1)$ \\
Others & 3846 & 2906 & 4195 & $3649(2)$ \\
Total & 27247 & 25062 & 23776 & $25362(13)$ \\
Insecticides & 16957 & 22527 & 11737 & $17074(8)$ \\
Irrigation & 6961 & 3952 & 3345 & $4753(2)$ \\
Int. on opt. capital & 3835 & 3549 & 3631 & $3672(2)$ \\
Total variable cost & 168178 & 155669 & 159251 & $161033(79)$ \\
B. Fixed cost & & & & \\
Family labour & 19220 & 22021 & 21860 & $21033(10)$ \\
Land use cost & 22249 & 21407 & 22155 & $21937(11)$ \\
Total fixed cost & 41469 & 43428 & 44015 & $42970(21)$ \\
Total cost (A+B) & 209647 & 199097 & 203266 & $204003(100)$ \\
\hline
\end{tabular}

Source: Field Survey (2016-17), Parentheses indicates the percentage of total cost

\section{Cost of cultivation}

The cost of potato cultivation was estimated to be Tk. 204003 and Tk. 161033 per hectare on total cost and variable cost basis, respectively. The major share in total cost was seed (31\%), followed by chemical fertilizers (13\%) and land use cost $(11 \%)$. The cost of potato

cultivation in Rajshahi was found higher (Tk. 209647/ha) than Thakurgaon (Tk. 203266/ha) and Rangpur (199097/ha). due to the higher cost of human labour, land preparation and more use of DAP (Table 8 ).

\section{Profitability of potato cultivation}

The average yield of potato was 28 ton per hectare which was higher than the national average of $20.91 \mathrm{t} / \mathrm{ha}$ (BBS, 2015). Comparatively higher yield was recorded in Rajshahi (30 t/ha) followed by Rangpur (28 t/ha) and Thakurgaon (26 t/ha) (Table 9). Higher yield was obtained in Rajshahi due to better management. 
The gross return and gross margin of potato cultivation were Tk. 249819/ha and Tk.88786/ha respectively. Gross margin was found to be highest in Rajshahi (Tk. 126759) followed by Rangpur (Tk. 74302) and Thakurgaon (Tk. 65298). The net return of potato cultivation was Tk. 45816 per hectare. The benefit cost ratio was 1.22. Average cost of production of potato was found $7.39 \mathrm{Tk} / \mathrm{kg}$ and it was highest in Thakurgaon $(7.82 \mathrm{Tk} / \mathrm{kg})$ and lowest in Rajshahi $(6.99 \mathrm{Tk} / \mathrm{kg})$.

Table 9. Profitability of Potato cultivations in the study areas

\begin{tabular}{lccccc}
\hline \multicolumn{1}{c}{ Items } & Rajshahi & Rangpur & Thakurgaon & All \\
\hline Yield (t/ha) & 30 & 28 & 26 & 28 \\
A. Total cost: & & & & \\
Variable cost (Tk./ha) & 168178 & 155669 & 159251 & 163886 \\
Fixed cost (Tk./ha) & 41469 & 43428 & 44015 & 42970 \\
B. Gross return (Tk./ha) & 294937 & 229971 & 224549 & 249819 \\
C. Gross margin (Tk./ha) & 126759 & 74302 & 65298 & 88786 \\
D. Net return (Tk./ha) & 85290 & 30874 & 21283 & 45816 \\
E. Benefit cost ratio & 1.41 & 1.16 & 1.10 & 1.22 \\
F. Cost (Tk/kg) & 6.99 & 7.11 & 7.82 & 7.39 \\
\hline
\end{tabular}

\section{Farmers' attitude towards BARI released potato varieties}

Table 10 revealed that about $66 \%$ farmers willing to increase the cultivation of BARI released potato varieties in the next year. Higher yield $(83 \%)$ ranked first behind the reasons for increasing potato cultivation followed by profitability $(70 \%)$, easy production technology (57\%) and short duration (47\%). On the other hand, 34\% farmers were not interested to increase cultivation of BARI released potato varieties due to high infestation of insect and diseases (87\%), high price of seed (73\%), lack of capital (51\%) and inadequate storage facilities (48\%).

Table 10. Reasons for increasing BARI released potato varieties for the next year

\begin{tabular}{|c|c|c|c|c|}
\hline \multirow{2}{*}{ Type of Facility } & \multicolumn{4}{|c|}{ Farmers responded $(\%)$} \\
\hline & Rajshahi & Rangpur & Thakurgaon & All \\
\hline \multicolumn{5}{|l|}{ A. Willingness to increase } \\
\hline 1. Yes & 73 & 62 & 58 & 66 \\
\hline 2. No & 27 & 48 & 62 & 34 \\
\hline \multicolumn{5}{|l|}{ B Reasons for increasing } \\
\hline 1. Higher yield & 91 & 82 & 76 & 83 \\
\hline 2. Profitable crop & 78 & 62 & 71 & 70 \\
\hline 3. Easy production technology & 53 & 69 & 49 & 57 \\
\hline 4. Short duration crop & 44 & 53 & 42 & 47 \\
\hline \multicolumn{5}{|l|}{ C. Reasons for not increasing } \\
\hline $\begin{array}{l}\text { 1. High infestation of insect and } \\
\text { diseases }\end{array}$ & 84 & 98 & 78 & 87 \\
\hline 2. High price of seed & 76 & 73 & 69 & 73 \\
\hline 3. Lack of capital & 51 & 56 & 47 & 51 \\
\hline 4. Inadequate storage facilities & 56 & 47 & 42 & 48 \\
\hline
\end{tabular}




\section{Constraints of potato cultivation}

The farmers in the study areas encountered different constraints during potato cultivation. The constraints were ranked based on their priority (Table 11). A brief discussion on various problems has been made in the following sections.

Insect and diseases infestation: Late blight (LB) disease is the aqute problem in potato cultivation. This was mentioned by $76 \%$ farmers. The yield of potato is seriously hampered by this disease. Although farmers have little knowledge about the harmful effects of disease incidence in potato. Generally farmers apply pesticide without recommendation in their field.

Non-availability of quality seed: Quality seed is the pre-requisite for higher yield of potato. Farmers in the study areas used potato seed from different sources like own source, BADC, market traders, etc. Market traders usually adulterate potato seed for receiving higher profit. Seed supplied by BADC is good but they supplied a small amount of seed, which do not meet the farmers' requirement and also the price of BADC seeds is very high. Nonetheless, own seed retained for their own use don't fulfill their requirements. Therefore, $70 \%$ respondent mentioned that non-availability of quality seed is a problem which hampered the potato yield.

Table 11. Constraints to potato cultivation in the study areas

\begin{tabular}{l|c|c|c|c}
\hline \multirow{2}{*}{\multicolumn{1}{c|}{ Constraints }} & \multicolumn{4}{c}{ Farmer responded (\%) } \\
\cline { 2 - 5 } & Rajshahi & Rangpur & Thakurgaon & All \\
\hline Insect and disease & 78 & 84 & 64 & 76 \\
$\begin{array}{l}\text { Non-availability of } \\
\text { seed }\end{array}$ & 76 & 64 & 71 & 70 \\
High price of inputs & 71 & 53 & 67 & 64 \\
Impure fertilizer & 56 & 53 & 62 & 57 \\
Inadequate storage facilities & 51 & 47 & 40 & 46 \\
Lack of training/knowledge & 29 & 22 & 33 & 28 \\
Others* & 27 & 16 & 20 & 21 \\
\hline
\end{tabular}

*Others mean high price of insecticides, lack of capital, low price of product etc.

High price of input: Sixty four percent farmers opined that the cost of production of potato is high. Farmers have to spend a large amount of money in the form of seed, labour and fertilizer. Such a high cost prevents the farmers to expand the area under potato cultivation.

Impure fertilizer: About 57\% farmers have identified the problem of adulteration and artificial scarcity of fertilizer. Farmers also informed that the dishonest traders try to create artificial scarcity through hoarding in the peak season for getting higher profit. 
Lack of technical knowledge: Technical knowledge relating to crop cultivation is also crucial for getting higher yield. It optimize input use, save production cost and increase yield of crops as well as farmers' income. Respondent farmers $(28 \%)$ in the study areas were suffering from lack of technical knowledge regarding potato cultivation since they used various inputs unwisely. Therefore, this problem was reported to be an important problem of potato cultivation.

Inadequate storage facility: Potato is a semi perishable vegetable which needs storage for using it throughout the year. The small and medium farmers have to sell most of their potatoes immediately after harvesting with lower price. Most of them have little access to the local cold storage because of their small volume. Therefore, inadequate storage facility $(46 \%)$ reported to be a problem in the study areas.

\section{Conclusions and Recommendations}

The study shows that BARI Alu-7 is a highly adopted potato variety in the study areas followed by BARI Alu-13, BARI Alu-25 and BARI Alu-8. Adoption index in ploughing is over use and adoption level of sowing date is high. Adoption level of seed rate, gypsum and boron were found higher in the study areas. The adoption level of urea, TSP, MoP was over use and adoption levels of cowdung and zinc sulphate were found medium. Most of the farmers collected potato seeds from other sources. Mostly one and two times earthing up, 5-8 times insecticides application and 1-4 times irrigation was practiced by the farmers in the study areas. Yield of potato was found higher at Rajshahi followed by Rangpur and Thakurgaon. Gross return, gross margin and net return also found higher in Rajshahi than Rangpur and Thakurgaon. Farmers' attitudes towards BARI released potato varieties seem to be very positive because most of the farmers wanted to increase potato production in the next year. Although potato cultivation is profitable, it faces various constraints like unavailability of quality seed, high price of inputs, insect and diseases, inadequate storage facilities etc.

Based on the findings, the following recommendations are put forward for wider adoption of BARI released potato varieties at farm level:

- BARI released potato seed should be made available to the farmers. So it should be need to encourage private seed companies to come forward for producing quality seed of potatoes.

- Motivational campaign through providing training, booklets and other supporting materials to farmers and extension personnel about the latest improved potato varieties should be continued.

- More intensive research should be undertaken by the breeders to develop disease and insect-pest resistant potato varieties in the near future. 
- Farmers level low cost storage facilities should be developed. Therefore, emphasis should also be given to increase the number of cold storage in the potato growing areas of the country.

\section{References}

Akhtar, M.E., M.S. Ali, Z.N. Huq, A. K. M. A. Habib, M. A. Hoque and A.B. S. Hossain. 1998. Problems and prospects of Tuber Crops in Bangladesh. proceeding. Workshop on Transfer of Technology of CDP crops and Research Extension linkage programme. Oct. 22-27, 1994, BARI, Joydebpur, Gazipur-1701, Bangladesh Pp. 213-220.

Ali, M. S. and A. Hoque. 2011. Potato for food Security in SAARC Countries; SAARC Seed Congress and Fair 2011, Dhaka, Bangladesh.

Amin, M. R. and M. R. Islam. 2009. Adoption of recommended potato production practices by the farmers in some selected areas of Naogaon District. Bangladesh Journal of Extension Education 21(1 \&2): 125-132.

Begum M. E., M.A. Miah. and M.A. Rashid. 2017. Socio-economic Determinants of Modern Potato Varieties Adoption and Resource use Efficiency in Northern Bangladesh. Annual Report, Agricultural Economics Division, BARI, Joydebpur, Gazipur.

BBS (Bangladesh Bureau of Statistics), 2016. Year book of Agricultural Statistics of Bangladesh, Statistical Division, Ministry of Planning, Government of the People's Republic of Bangladesh, Dhaka, Bangladesh.

Elias, S.M., M. R. U. Miah, M. J. Hossain, G. S. Torofder and M. S. Islam. 1992. Effect of potassium on the growth and yield of potato. Bangladesh J. Agril. Res. 17(7): 9193.

Haque M A, M.A Miah. and S. Hossain. 2011. Adoption and Profitability of BARI Released Potato Varieties at Farm Level in Selected Areas of Bangladesh. Annual Report, Agricultural Economics Division, BARI, Joydebpur, Gazipur.

Gupta, D.D, and S. Chowdhury, 2002. Agro Technology Transfer Programme. An Assessment. Mittal Publications, A-110, Mohan Garden, New Delhi-110059, India. P. 83.

Kabir, K. H. and M. Z. Haque, 2012. Alu Chasher Adunik Kolakowshol (Modern Production Technologies of Potato), Tuber Crops Research Centre, Bangladesh Agricultural Research Institute, Gazipu-1701, Bangladesh:51-54. 